\title{
potpc|q5229-.T/ \\ SURFACE MODIFIED COALS FOR ENHANCED \\ CATALYST DISPERSION AND LIQUEFACTION
}

First Report for the Period

September 1, 1995 to February 29, 1996

$\therefore$

Godfried M. K. Abotsi

Principal Investigator

Department of Engineering

Clark Atlanta University

Atlanta , Georgia 30314

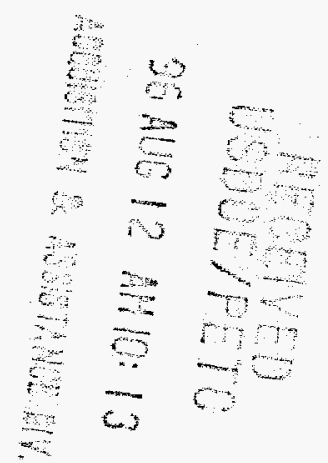

PREPARED FOR THE UNITED STATES DEPARTMENT OF ENERGY

UNDER CONTRACT NUMBER DE-FG22-95PC95229

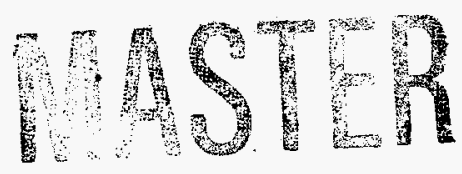




\section{DISCLAMER}

Portions of this document may be illegible in electronic image products. Images are produced from the best available original document. 


\section{ABSTRACT}

The aim of this work is to enhance catalyst loading and dispersion in coal for improved liquefaction by preadsorption of surfactants onto coal. The application of surfactants to coal beneficiation and coal-water slurry preparation is well known. However, the effects of surfactants on catalyst loading and dispersion prior to coal liquefaction have not been investigated. The current work is focused on the influence of the cationic surfactant dodecyl dimethyl ethyl ammonium bromide (DDAB) and sodium dodecyl sulfate (SDS, anionic) on the surface properties of a bituminous coal and its molybdenum uptake from solution. The results show that DDAB created positively charged:sites on the coal and increased molybdenum loading compared to the original coal. In contrast, SDS rendered the coal surface negative and reduced molybdenum uptake. The results show that efficient loading of molybdenum catalyst onto coal can be achieved by pretreatment of the coal with dodecyl dimethyl ethyl ammonium bromide. 


\section{INTRODUCTION}

The goal of this work is to modify coal surface properties by adsorbing surfactants and thereby improve catalyst adsorption and dispersion, and enhance coal liquefaction activities. Coal surface contains both hydrophobic and hydrophilic sites. However, this dual character of coal surface is generally not taken into consideration when loading coal with catalysts from organic solutions. When added from organic solutions, the catalyst will be attracted to the organic sites on the coal but it will be repelled by the hydrophilic sites. This will produce an uneven distribution of the catalyst on the coal, result in poor catalyst dispersion, and produce low liquefaction activity. By adsorbing appropriate surfactants onto: coat the hydrophilic heads of the surfactants will be adsorbed onto the oppositely charged sites on the coal while the organic portions will be orienied towards the organic solution. This will promote hydrophobic interaction between the hydrophobic catalyst solution and the catalyst precursor.

The high liquefaction activities of molybienum compounds are well known (1-3). The catalyst may be sulfided in-situ or converted into the sulfide form by the sulfur in the coal. Previous reports showed that improved techniques for molybdenum dispersion in coal are needed to improve its !iquefaction activity. The aim of this work is to entance molybdenum loading and dispersion in coal by pretreatment with surfactants. In the current report, the effects of sodium dodecyl sulfate (SDS) and dodecyl dimethyl ethyl ammonium bromide (DDAB) on molybdenum adsorption by a bituminous coal are discussed. 


\section{EXPERIMENTAL}

The Illinois No.6 coal (DECS-24) used in this study was supplied by the Penn State Coal Sample Bank. Its moisture, ash, volatile matter, and fixed carbon contents were $13.2,11.6,35.4$, and $39.7 \%$ wt., respectively, on as-received basis. It has an ultimate analysis of $11.6 \%$ ash, $57.3 \%$ carbon, $4.0 \%$ hydrogen, $1.0 \%$ nitrogen, $4.8 \%$ sulfur, and $8.1 \%$ wt. oxygen (by difference). Coal-water slurries were prepared by adding $2.0 \mathrm{~g}$ of coal to $25 \mathrm{~mL}$ of $0.01 \mathrm{M}$ aqueous solution of molybdenum and $25 \mathrm{~mL}$ of $0.02 \mathrm{M}$ SDS or $0.02 \mathrm{M} \mathrm{DDAB}$. A set of six samples were prepared for each surfactant and the pHs of the slurries ranged from about $\mathrm{pH} 2$ to 12 . Ammonium molybdate (VI) tetrahydrate (AMT) was used as the molybdenum source. After recording the original pHs of the coal dispersions, a few drops of $1 \mathrm{M} \mathrm{HCl}$ or $0.5 \mathrm{M} \mathrm{NaOH}$ solution were added to all, except one sample, to adjust the pHs to the desired values. Two sets of the coal-water slurries, one set without surfactants and the other without cozl, were used as controls. The samples were shaken on a mechanical shaker for $24 \mathrm{~h}$, followed by redetermination of the final equilibrium pHs. The samples were then filtered and the filtrates were analyzed for molybdenum using atomic absorption spectrophotometry. The molybdenum content of the coal residues was determined by Galbraith Laboratories, Knoxville, TN:

To determine the effects of the coal surface charge properties on the adsorption of the surfactants and molybdenum, the zeta potentials of coal-water slurries containing $5 \mathrm{~g}$ of coal per liter and deionized water were measured. The measurements were conducted on $25 \mathrm{~mL}$ samples to which $25 \mathrm{~mL}$ of $0.2 \mathrm{M}, 0.02 \mathrm{M}$, or $0.002 \mathrm{M} \mathrm{DDAB}$ solution had been added. The pHs of the samples were measured and then adjusted with acid or base as described above. The samples were equilibrated for 4 hours by mechanical agitation using a Burrel Wrist Action Shaker and the equilibrium pH of each sample was 
recorded. The zeta potential of each sample was measured at room temperature using a Pen Kem Model 501 zeta meter. Similar studies are on SDS-containing samples are in progress. Details of the procedure have been provided previously (4-6).

The interaction of the surfactants with the coal surface was studied using diffuse reflectance FTIR. The coal samples were dispersed in infrared grade $\mathrm{KBr}$ that had been dried overnight at $300^{\circ} \mathrm{C}$ and sieved through a 90 micron sieve. The FTIR spectra were recorded on $10 \%$ coal in KBr using a Nicolet Magna IR Spec 750 and 500 scans.

\section{RESULTS AND DISCUSSION}

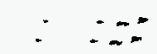

The effects of the surfactants and $\mathrm{pH}$ on molybdenum loading onto the coal are showr: in Figure 1. A remarkable dependence of catalyst loading on both parameters was observed. The minimum catalyst loading occurred on the parent, untreated coal whereas the DDAB-treated coal had the highest molybdenum content. Around $\mathrm{pH} 2.5$, the molybdenum loadings of these samples were about 5 and $15 \%$ wt., respectively. An intermediate molybdenum loading occurred on the SDS-treated coal.

The zeta potential results in Figure 2 showed that the coal is negatively charged within the $\mathrm{pH}$ range investigated and that the charge density increased with increase in the slurry $\mathrm{pH}$. This behavior has been explained previously $(4,5)$. Figure 2 shows that the coal particles generally acquired positive zeta potentials on addition of DDAB. SDS $\left(\mathrm{CH}_{3}\left(\mathrm{CH}_{2}\right)_{11} \mathrm{OSO}_{3}-\mathrm{Na}^{+}\right)$and $\mathrm{DDAB}\left(\mathrm{CH}_{3}\left(\mathrm{CH}_{2}\right)_{11} \mathrm{~N}\left(\mathrm{C}_{2} \mathrm{H}_{5}\right)\left(\mathrm{CH}_{3}\right)_{2}+\mathrm{Br}\right)$ will dissociate in solution to produce anionic and cationic surfactants, respectively. Since DDAB is cationic, the positive charge density on the coal can be explained by the coulombic attraction of the surfactant to the coal surface and its subsequent adsorption. 
The observed molybdenum adsorption patterns can be explained by the electronic charges on the coal surface and on the molybdenum species. In aqueous solution, AMT will dissociate to form various molybdenum oxyanions (7). Thus, the adsorption of the molybdenum species should be promoted by the positively charged DDAB sites on the coal. From Figure 2, it is observed that at $10^{-3} \mathrm{MDDAB}$, the zeta potentials are positive and become negative above $\sim \mathrm{pH}$ 9. At $10^{-2} \mathrm{MDDAB}$, the zeta potentials are positive within the entire range of $\mathrm{pH}$ studied and they increased almost exponentially with increase in $\mathrm{pH}$. This implies progressively stronger adsorption of DDAB. When the $\mathrm{DDAB}$ concentration was raised to $10^{-1} \mathrm{M}$, the zeta potential increased steadily, passed through a maximum around $\mathrm{pH} 6-8$, and then decreased thereafter. This phenomenon is attributed to strong $D D A B$-adsorption ard micelle formation. When the DDAB concentration on the surface exceeded the critical micelle concentration around $\mathrm{pH}$ 6-8, the molecules formed aggregates with the polar head of the surfactant oriented towards the interior of the micelle. This should decrease the positive charge density on the coal, as was indicated by the decline in the zeta potential values.

The FTIR spectra of the original, untreated coal and those onto which molybdenum and DDAB or SDS were adsorbed are shown in Figure 3. The FTIR specirum for the original coal after loading with molybdenum alone is provided in Figure 3A. Significant differences can be seen in the $\mathrm{C}-\mathrm{H}$ bands at $2800-3000 \mathrm{~cm}^{-1}$. The intensities of these bands are higher for the surfactant-treated coals than for the raw coal (Figure $3 B$ ). It is also noted that the intensity of the DDAB-treated coal (Figure $3 C$ ) is stronger than for the SDS-treated specimen (Figure 3D). The FTIR spectra confirm the adsorption of the surfactants onto the coal surface.

In conclusion, it has been shown that the uptake of molybdenum catalyst is significantly promoted by preadsortion of sodium dodecyl sulfate and dodecyl dimethyl ammonium 
bromide onto the surface of Illinois No. 6 coal, DECS-24. DDAB effected higher catalyst loading since its cationic character favored its adsorption onto the negatively charged coal surface. This study showed that the surface properties of coal can be engineered for effective catalyst loading onto coal. The influence of the catalyst on coal liquefaction activities will be discussed in subsequent reports.

\section{REFERENCES}

(1) Weller, S. W., Pelipetz, M. G., Ind. Eng. Chem. 1951, 43, 1243.

(2) Yamashita, H., Ohtsuka, Y., Yoshida, S., Tomita, A. Energy \&Fuels 1989, 3,586 .

(3) Pradhan, V. R.; Herrick, D. E.; Tierney, J. W., Wender, I., Huffman, G. P., Energy \& Fueis 1991, 5, 497.

(4) Abotsi, G. M. K., Bota, K. B., G. Saha, Energy \& Fuels, 1992, 6, 779.

(5) A botsi, G. M. K., Bota, K. B., G. Saha, Fuel Sc. Tech. Init., 1993, 11, 327.

(6) Bota, K. B., Abotsi, G. M. K., L. L. Sims, Energy \&Fuels, 1994, 8, 937.

(7) Honig, D. S., Kustin, K., Inorg. Chem., 1972, 11, 65. 

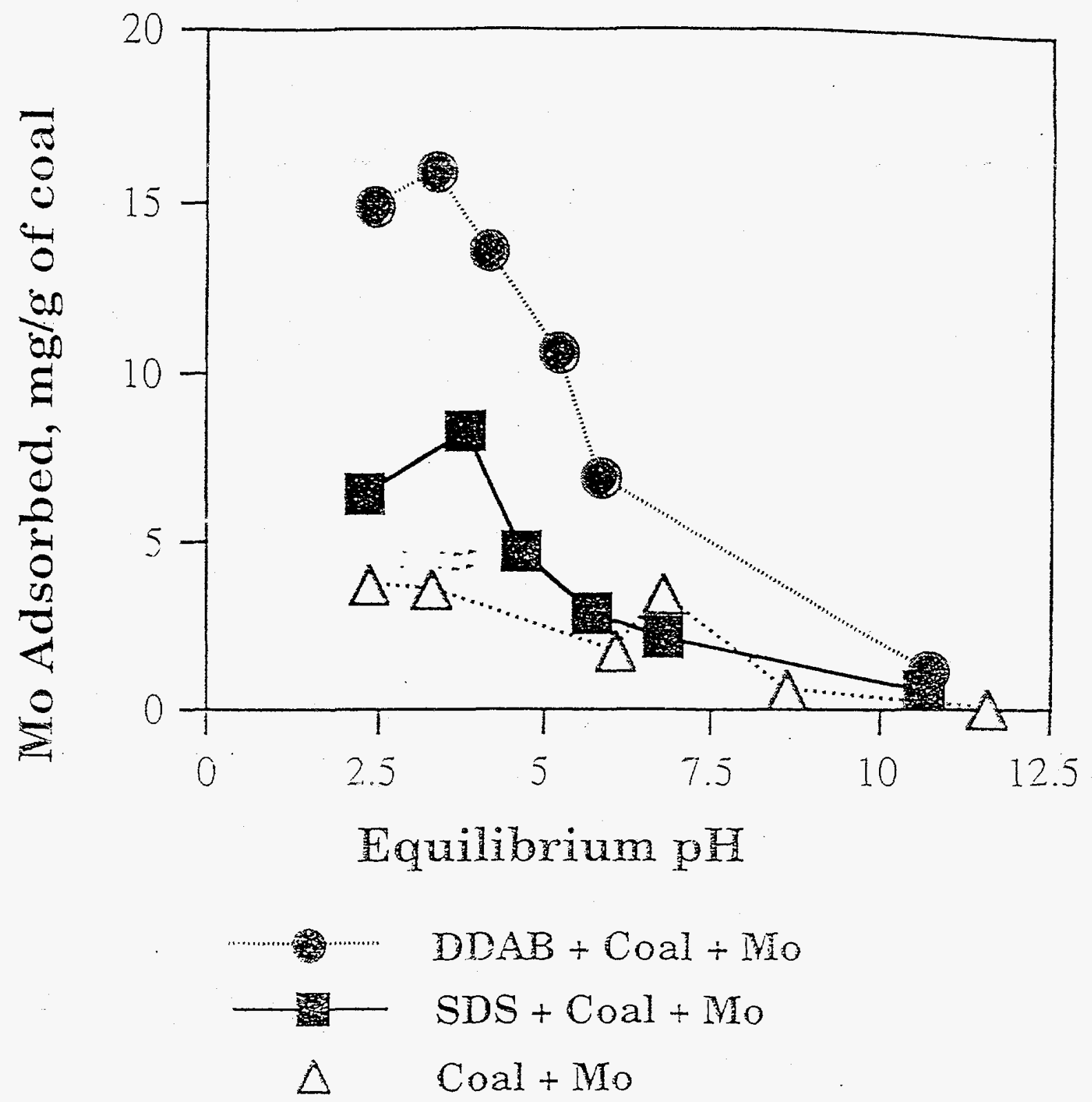

Figure 1. Effects of surfactant and $\mathrm{pH}$ on molybdenum adsorption by Illinois No. 6 coal, DECS-24. 


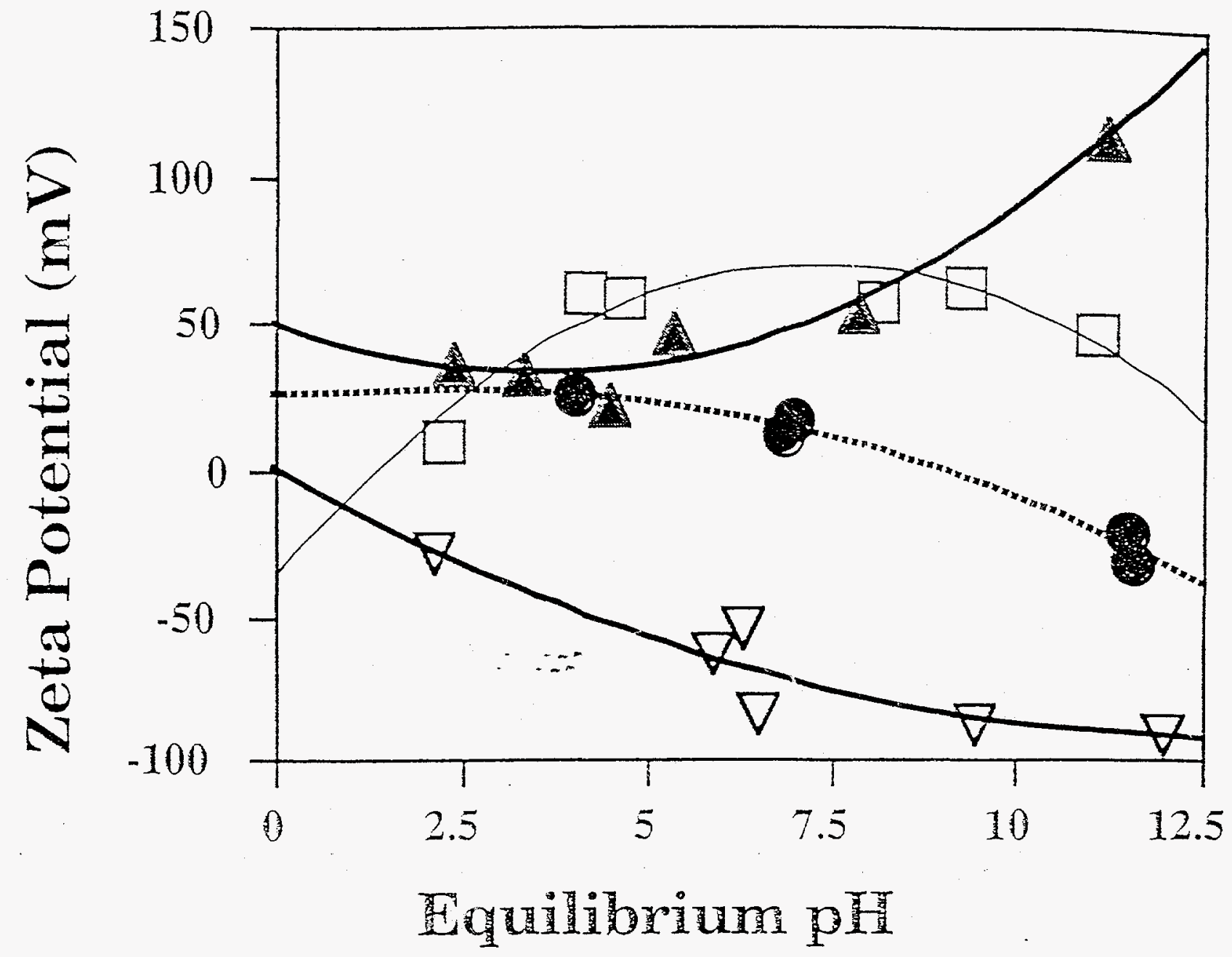
$10^{-3} \mathrm{M} D \mathrm{DAB}$
$10^{-2}$ IDAB
$10^{-1}$ M DDAB
Original DECS-24 Coal

Figure 2. Effect of dodecyl dimethyl ethyl ammonium bromide on the zeta potentials of the coal. 


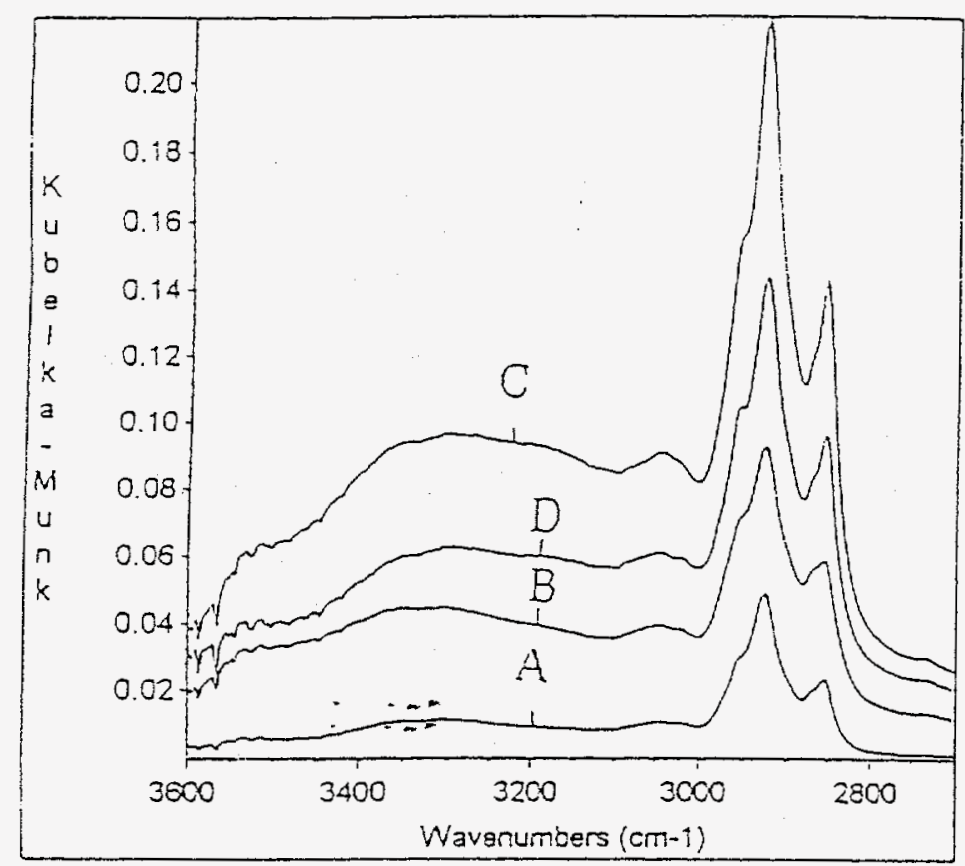

\section{A: Coal + Mo $\quad$ B: Original Coal \\ $\mathrm{C}: \mathrm{Coal}+\mathrm{DDAB}+\mathrm{Mo} \quad \mathrm{D}: \mathrm{Coal}+\mathrm{SDS}+\mathrm{Mo}$}

Figure 3. FTIR spectra of the coal before and after surfactant and molybdenum adsorption. 